University of Wollongong

Research Online

Sydney Business School - Papers

Faculty of Business and Law

2011

\title{
Modelling Corporate Competitive Capabilities for SMEs in the Malaysian Manufacturing Sector: An Exploratory Study
}

Siti Nur 'Atikah Zulkiffli

University of Wollongong, snaz167@uowmail.edu.au

Nelson Perera

University of Wollongong,nperera@uow.edu.au

Follow this and additional works at: https://ro.uow.edu.au/gsbpapers

Part of the Business Commons

\section{Recommended Citation}

Zulkiffli, Siti Nur 'Atikah and Perera, Nelson: Modelling Corporate Competitive Capabilities for SMEs in the Malaysian Manufacturing Sector: An Exploratory Study 2011.

https://ro.uow.edu.au/gsbpapers/314

Research Online is the open access institutional repository for the University of Wollongong. For further information contact the UOW Library: research-pubs@uow.edu.au 


\title{
Modelling Corporate Competitive Capabilities for SMEs in the Malaysian Manufacturing Sector: An Exploratory Study
}

\author{
Abstract \\ This study empirically tests the relationship between the four factors of corporate competitive \\ capabilities (CCC) (cost leadership, differentiation, innovative marketing and customer service) and \\ business performance. The study specifically emphasises small and medium enterprises (SMEs) in \\ Malaysia. The study's quantitative approach is based on the responses of 135 Malaysian manufacturing \\ SMEs responded to a postal questionnaire. Empirical results from structural equation modelling (SEM) \\ demonstrate an insignificant relationship between $\mathrm{CCC}$ and business performance.

\section{Keywords} \\ era2015 \\ Disciplines \\ Business

\section{Publication Details} \\ Zulkiffli, S. \& Perera, N. (2011). Modelling Corporate Competitive Capabilities for SMEs in the Malaysian \\ Manufacturing Sector: An Exploratory Study. 2011 SIBR Conference on Interdisciplinary Business and \\ Economics Research (pp. 1-10). Bangkok, Thailand: Society of Interdisciplinary Business Research.
}




\title{
MODELLING CORPORATE COMPETITIVE CAPABILITIES FOR SMES IN THE MALAYSIAN MANUFACTURING SECTOR: AN EXPLORATORY STUDY ${ }^{\mathrm{a}}$
}

\author{
Siti Nur 'Atikah Zulkiffli ${ }^{\mathrm{b}}$ and Nelson Perera ${ }^{\mathrm{c}}$ \\ This paper has been double-blind peer reviewed by an international panel of SIBR
}

\begin{abstract}
$\underline{\text { Abstract }}$
This study empirically tests the relationship between the four factors of corporate competitive capabilities (CCC) (cost leadership, differentiation, innovative marketing and customer service) and business performance. The study specifically emphasises small and medium enterprises (SMEs) in Malaysia. The study' quantitative approach is based on the responses of 135 Malaysian manufacturing SMEs responded to a postal questionnaire. Empirical results from structural equation modelling (SEM) demonstrate an insignificant relationship between CCC and business performance.
\end{abstract}

Key words: corporate competitive capabilities, business performance, small and medium enterprises, Malaysia.

\section{Introduction}

Today, many firms realise the importance of capability to the development of small and medium enterprises (SMEs). Capability can be defined as firms' internal and external organisation skills, resources and functional competencies to meet the requirement of the changing economic environment (Teece et al., 1997). It also can be referred to as "the exploitation of specific practices to attain performance gains" (Narasimhan et al., 2005, p. 1014). These definitions imply that some practical aspects may affect the exploitation of specific capabilities.

The major focus of empirical research on capability to date has been on developed countries in the West (Stalk et al., 1992; O'Regan \& Ghobadian, 2004); the existence and implications of the capability concept have not been closely examined in other contexts, particularly the context of developing countries. For example, while the progress of SMEs' development in Malaysia has been examined in a number of studies (among others, Ndubisi \& Salleh, 2006; Meena \& Anil, 2007; Jusoh \& Parnell, 2008), Malaysia has been the subject of only very limited empirical study regarding capability, particularly as it relates to SMEs.

Thus, the presence of Corporate Competitive Capabilities (CCC) is imperative to Malaysian SMEs. In this study, CCC can be referred as distinctive competence as expressed in firms' specific abilities. Firms must recognise their abilities to compete effectively in domestic and international markets. If SMEs in Malaysia do not seek to improve their competitive capabilities, their business may fail, particularly during the economic recession period. This study measures the four factors of CCC - cost leadership, differentiation,

\footnotetext{
${ }^{\mathrm{b}}$ Corresponding author. University of Wollongong, Australia and Universiti Malaysia Terengganu, Malaysia. email: snaz167@uowmail.edu.au.

c University of Wollongong, Australia. email: nperera@uowmail.edu.au.
} 
innovative marketing and customer service - and their relationship with business performance; the result can provide guidance to business wanting to develop an optimal mix of competencies to improve their competitiveness.

This study focuses on SMEs in the manufacturing sector in Malaysia, as this sector predominantly contributes to the growth of SMEs and is an important engine for the economy of many countries (Tambunan, 2007). The manufacturing sector also characteristically adopts clearer strategies with higher levels of fixed commitment compared to other sectors (Swartz \& Iacobucci, 2000). In Malaysia, this sector has outperformed the economy as a whole since 2005, contributing overall added value ranging from 29.3 percent in 2005 to 30.4 percent in 2009 (NSDC, 2010).

The first part of this paper focuses on an analysis of the literature concerning the four factors of CCC (cost leadership, differentiation, innovative marketing and customer service). This is followed by the justification of the research hypothesis, the methodology, the data analysis and, finally, the discussion and conclusions.

\section{Literature Review}

Corporate competitive capabilities (CCC) are necessary for a firm to develop core competence, and to generate a good business strategy. It is common to have many substantial differences in capabilities and resource allocation across individual companies that pursue the same strategy. Such differences could significantly affect corporate performance (Narasimhan et al., 2001). Some pioneer scholars refer to CCC as a competitive strategy or corporate strategy (Andrews, 1980; Watts et al., 1992) and a manufacturing task (Miller \& Roth, 1994). This literature reviews the four factors of CCC: cost leadership, differentiation, innovative marketing and customer service.

\section{a. Cost Leadership}

In general, cost leadership requires a set of functional policies, such as aggressive construction of efficient-scale facilities, vigorous reductions of cost, tight control of cost and overhead, avoidance of marginal customers and cost minimisation in all functional areas. According to Porter (1980), these policies help firms provide products at a lower cost than their competitors. To be pioneers in cost leadership, firms need to consider differentiation together with a cost-leadership strategy in providing a competitive price (Porter, 1985).

Allen et al.'s field study (2007) reveals that Japanese firms far more frequently used a cost-leadership strategy (41.4 percent) than a differentiation strategy (7.6 percent). Costleadership (or cost-minimisation) strategies are used to reduce cost and tightly control overheads. Cost-leadership strategies simultaneously improve customer service as well.

Jusoh and Parnell (2008) find that Malaysian customers tends to make purchasing decisions based on price rather than the product's uniqueness and innovativeness. Most Malaysians have low purchasing power, and have thus developed very conservative buying habits, only considering affordable products. Jusoh and Parnell (2008) reject the earlier findings of Kim (2006a; 2006b) where both cost leadership and differentiation measure the competitive capabilities of a firm.

Pearce and Robinson (2000) contend that the simple management structure of most SMEs is one of the traits of a cost-leadership strategy. However, Hunger and Wheelen (1999) assert that SMEs must also concentrate on deliberately developing a cost-leadership strategy, as they usually do not engage in the innovative practice that is key to an effective differentiation strategy. A cost-leadership strategy is also crucial to SMEs' ability to produce lower-cost products with the same quality as those from large firms. However, few new entrants will be able to match the leaders' competitive advantage, which forms a barrier to 
entry. As a result, firms that can enter - and survive in - the market will earn an aboveaverage return on investment (Hunger \& Wheelen, 1999).

\section{b. Differentiation}

Another approach to achieving competitive advantage is differentiation strategy. According to Kim (2006a; 2006b) differentiation strategy is part of corporate competitive capabilities (CCC), and can be defined as creating something that is perceived to be unique industry-wide (Porter, 1980; Porter, 1985). Many firms seek to produce products that are different from those of their rivals. Differentiation can be manifested in design or brand image, technology, features, customer service, dealer network or any other pertinent dimensions. Significantly, firms often differentiate themselves using several of these dimensions at a time and by providing valuable features, rather than offering lower prices to potential buyers. This strategy also can add value to the product and therefore, the company can set a higher price, which reflects the firm's performance (Porter, 1980; Porter, 1985).

However, according to Cousins (2005), firms should focus on differentiation strategy based on supply chain management (SCM), which can allow them to achieve competitive advantage by manipulating their competencies and capabilities, and by treating SCM as the firm's core capability. Cousins (2005) also emphasises that differentiation strategy requires a much broader and strategic view of the supply chain's role within a firm. Similarly, Marcus (1997) stresses that the major factor of differentiation strategy is to seek suppliers offering equivalent quality to the firm.

In Malaysia, the electrical and electronic industry demonstrates that differentiation strategy enhances export performance 16.6 percent more than other strategies (Rashid \& Chacko, 1999). From the perspective of SMEs, the implementation of differentiation strategy demonstrates positive relationships with performance and competitiveness (Wafa et al., 2005). However, another opinion emphasises SMEs' difficulty in successfully implementing a differentiation strategy (Lee et al., 1999). This suggests that a combination of differentiation strategy with other competitive advantages may be the key to a firm's performance (Bullón, 2009). Therefore, firms are encouraged to consider their service capabilities and strengths in differentiating themselves from competitors (Marcus, 1997).

\section{c. Innovative Marketing}

In practice, SME's marketing efforts are driven by innovation. The concept of innovative marketing in SMEs is based on the recognition of engagement in marketing by managers. In general, the marketing objective for SMEs is to generate sales and profit (Cummins et al., 2000; O'Dwyer et al., 2009a).

The idea of innovation marketing was pioneered by Drucker in 1955 in the book The Practice of Management. In the 1989 version of the book, Drucker (p. 35) emphasises innovative marketing, saying, "there is only one valid definition of business purpose: to create a customer...it is a customer who determines what the business is....Because it is its purpose to create a customer, any business enterprise has two - and only these two - basic functions: marketing and innovation". Thus, firms need to provide the finest "concept, tools and infrastructure to close the gap between innovation and market positioning to achieve sustainable competitive advantage" (Gardner, 1991, p. 18).

The study of O'Dwyer et al. (2009b) demonstrates that emergent innovative concepts such as SME image, strategic alliance and product quality are important to the development of innovative marketing activities and practices. Using these, the mix of target markets and the quality of service to the chosen markets can be improved (Johne, 1999). It is also important for firms to assess the effectiveness of their marketing, and the technical capability 
and product innovation that underlie it, so they can develop their reputation, and hence gain new customers and retain existing customers (Allen et al., 2007).

\section{d. Customer Service}

As the final element of $\mathrm{CCC}$, customer service demonstrates a positive and significant impact on cognitive attitudes, repurchase intention and customer satisfaction. Moreover, it plays a major role in accomplishing customer satisfaction; it also plays a role in increasing the level of physical distribution and logistics (Innis \& La Londe, 1994). As the most important feature of customer service, delivery (which covers both information and product) is highly consistent with several features of marketing differentiation strategy (Swink \& Hegarty, 1998). Customer service also contributes to the supply system, as it significantly relates to all functions along the supply chain process (Stevens, 1989).

Valsamakis and Sprague's 2001 study shows a positive relationship between SMEs and customers in the UK market across the supply chain process. In general, SMEs prefer to focus on customers' well-being rather than on the manufacturing of physical products. On the other hand, customer service can also be delivered through an efficient online system. According to one study of 395 SMEs in the US through the adoption of competitive advantage through use of the internet, online ordering capabilities have a positive impact on perceived sales and online product demonstrations, and engaging customer service through email shows positive impacts on perceived net profits (Levenburg \& Klein, 2006). This suggest that the adoption of online customer service is significant for SMEs, as they have limited mobility in terms of workforce, technology and other resources to retain good relationships with customers.

These four factors could be grouped into a major domain which is corporate competitive capabilities (CCCC) (Kim, 2006a). The development of CCC within firms is necessary to develop a core competence, indeed to generate a good business strategy. In fact, it is common to have many substantial differences in capabilities and resources allocation across individual companies that pursue the same strategy. Such differences also could significantly affect corporate performance (Narasimhan et al., 2001).

\section{Hypothesis}

The study develops a hypothesis to be investigated and analysed through structural equation modelling (SEM) analysis. The development of the hypotheses is as follows:

In general, corporate competitive capabilities - particularly those with a strong connection to customer satisfaction and market performance - contribute to the improvement of business performance (Stevens, 1989; Watts et al., 1992; Rosenzweig et al., 2003). However, a conflict arises between external differentiation and internal cost leadership, which contributes to several types of competition-selection schemes (Prajogo, 2007). The literature demonstrates that there is a significant performance implication for firms that apply innovative marketing techniques (Thomas et al., 1991). From this perspective, the following hypothesis is proposed:

\section{Hypothesis: The greater a firm's corporate competitive capabilities, the better its business performance will be.}




\section{Methodology}

Prior to data collection, a pilot study was undertaken to refine the questionnaire with respect to the Malaysian business environment. Twelve respondents, randomly selected from the directory of the Federation of Malaysian Manufacturers (FMM, 2008), participated. Nine hundred fifty firms were chosen for the sample from 1,402 firms categorised as small and medium-sized. As the study is based on a quantitative approach through a postal questionnaire, the questionnaire sets were sent to a top manager in each firm in the sample. One hundred thirty-five usable questionnaires (a response rate of 14.2 percent) were returned.

\section{Data Analysis}

$\mathrm{CCC}$ and business performance were measured by items rated on a seven-point Likert scale. Structural equation modelling (SEM) was used to test the confirmatory factor analysis (CFA) and hypothesis of interest. The rationales for using SEM as a method for analysis were its ability to analyse the dimensionality of each factor and the fact that $\mathrm{CCC}$ and business performance were determined as second-order factor models.

First, the data was analysed for CFA on the four factors of CCC (cost leadership, differentiation, innovative marketing and customer service), and the five factors of business performance (market, supplier, process, people and customer relationship). All these factors were then analysed using a first-order and second-order factor approach to represent the CCC and business-performance constructs. Convergent, discriminant and nomological validity were also assessed; both constructs passed the assessment.

Then, the data was tested using a full structural model to investigate the relationship between CCC and business performance. As expected, the analysis showed that greater corporate competitive capabilities would not lead towards better business performance for Malaysian SMEs $(\lambda=.180, p>.05)$. Thus, the hypothesis is rejected. This finding is comparable to the study of Kim (2009) of small firms in Japan and Korea.

\section{Discussions and Conclusions}

This study found an insignificant correlation between CCC and business performance; thus it may be concluded that CCC seems not to have an important relationship with business performance. Also, it demonstrates that the achievement of SMEs in Malaysia does not rely absolutely on the ability to be more competitive.

The insignificant relationship between CCC and business performance for Malaysian SMEs is also empirically supported by a similar study by Man (2009), which examined the relationship between distinctive capabilities, innovativeness and strategy type and business performance for 121 manufacturing SMEs in Malaysia. In contrast, Cheng et al. (2006) in a study of SMEs in China, reported that competitive capabilities were the major contributor to the success of their regional economic development. Therefore, Malaysian SMEs should continue to give high focus to this factor despite this study's finding that it may not be pertinent to SMEs' business performance in Malaysia. This result may be due to a number of reasons, such as high prices for raw materials, reduction in demand, cash-flow and labour problems and the global financial crisis of 2008-9.

Indirectly, the findings demonstrate that the objectives of many programs designed to help Malaysian SMEs have not yet been achieved. This suggests that Malaysian SMEs can benefit from taking the initiatives to, themselves, focus on the development of their capability and capacity, particularly amongst their employees and managers. As indicated by Idrus et al. (2009), Malaysian SMEs have demonstrated among the highest rates of employee turnover in the world (19 percent and 22 percent for small and medium enterprises, respectively). 
Malaysian SMEs should consider more efficient plans that focus on developing their capacity for product and market innovation, gaining access to market intelligence and government support, funding and working capital, and hiring qualified workers.

This study is subject to some limitations. The first limitation relates to the fact that it focuses only on SMEs in the Malaysian manufacturing sector, and there is no certainty that its results can be generalised to other contexts. Second, it uses a limited set of important variables within the theoretical framework; future studies can potentially include other variables in the analyses.

This study may have some practical values for SMEs' managers, particularly in Malaysia. While the Malaysian Government has since 2008 introduced many action plans, initiatives and policies focusing on building capacity and capability, the current available programs, focus more on management and marketing, and less on other important factors such as the development of business relationships, competence, support networks and attitudinal capabilities to sustain a high level of business performance among SMEs in Malaysia.

This study has taken one step forward from the extant studies by proposing a study of RBV theory in the context of CCC from two difference perspectives: (i) a less-developed country (in this case, Malaysia) and (ii) firm size (small and medium firms with fewer than 150 employees). Also, this study contributes to the body of knowledge by providing new data and empirical insights into the relationship between CCC and business performance of SMEs in the Malaysian manufacturing sector. Thus, it demonstrates that potential benefits may be gathered by Malaysian SMEs from focusing on developing their capabilities, even though the hypothesis was rejected. 


\section{References:}

Allen, R. S., Helms, M. M., Takeda, M. B. \& White, C. S. (2007). Porter's generic strategies: An exploratory study of their use in Japan. Journal of Business Strategies, 24(1): 6990.

Andrews, K. R. (1980). The Concept of Corporate Strategy. Homewood, IL: Richard D Irwin.

Bullón, L. A. (2009). Competitive advantage of operational and dynamic information technology capabilities. Journal of Centrum Cathedra, 2(1): 86-107.

Cheng, H. Y., Zhang, D. M., Ye, M. \& Xia, J. (2006). Competitive capability evaluation for middle and small enterprises in regional industries. The Business Review, Cambridge, 5(2): 104.

Cousins, P. D. (2005). The alignment of appropriate firm and supply strategies for competitive advantage. International Journal of Operations \& Production Management, 25(5): 403 - 428.

Cummins, D., Gilmore, A., Carson, D. \& O'Donnell, A. (2000). Innovative marketing in SMEs: A conceptual \& descriptive framework. New Product Management \& Innovation Management, 2(3): 231-248.

Drucker, P. F. (1989). The Practice of Management. Oxford: Heinemann Professional Publishing Ltd.

FMM (2008). FMM Directory 2008 Malaysian Industries - Supplying the world with competitive products and services. Kuala Lumpur: Federation of Malaysian Manufacturers.

Gardner, D. M. (1991). Exploring the marketing/enterpreneurship interface. Research at the Marketing/Entrepreneurship Interface. Chicago, University of Illinois.

Hunger, J. D. \& Wheelen, T. L. (1999). Strategic Management Upper Saddle River, NJ: Prentice Hall.

Idrus, D., Salahudin, S. N., Baharin, N. L. \& Abdullah, M. S. (2009). Occupational content and turnover intention: A case study of small and medium sized enterprises. Malaysia Labour Review, 3(2): 63-73.

Innis, D. E. \& La Londe, B. J. (1994). Customer service: The key to customer satisfaction, customer loyalty, and market share. Journal of Business Logistics, 15(1): 1-27.

Johne, A. (1999). Successful market innovation. European Journal of Innovation Management, 2(1): 6-11. 
Jusoh, R. \& Parnell, J. A. (2008). Competitive strategy and performance measurement in the Malaysian context: An exploratory study. Management Decision, 46(1): 5-31.

Kim, S. W. (2006a). The effect of supply chain integration on the alignment between corporate competitive capability and supply chain operational capability. International Journal of Operations \& Production Management, 26(10): 1084-1107.

Kim, S. W. (2006b). Effects of supply chain management practices, integration and competition capability on performance. Supply Chain Management: An International Journal, 11(3): 241-248.

Kim, S. W. (2009). An investigation on the direct and indirect effect of supply chain integration on firm performance. International Journal of Production Economics, 119(2): 328-346.

Lee, K. S., Lim, G. H. \& Tan, S. J. (1999). Dealing with resource disadvantage: Generic strategies for SMEs. Small Business Economics, 12(4): 299-311.

Levenburg, N. M. \& Klein, H. A. (2006). Delivering customer services online: Identifying best practices of medium-sized enterprises. Information Systems Journal, 16(2): 135155.

Man, M. M. K. (2009). The relationship between distinctive capabilities, innovativeness, strategy types and the performance of small and medium-size enterprises (SMEs) of Malaysian manufacturing sector. The International Business \& Economics Research Journal, 8(11): 21-33.

Marcus, D. (1997). Create value via differentiation. Modern Casting, 87(12): 56.

Meena, C. \& Anil, S. L. (2007). An International Perspective on Internal Controls in Small and Medium Enterprises. The Business Review, Cambridge, 8(1): 80.

Miller, J. G. \& Roth, A. V. (1994). A taxonomy of manufacturing strategies. Management Science, 40(3): 285-304.

Narasimhan, R., Jayaram, J. \& Carter, J. R. (2001). An empirical examination of the underlying dimensions of purchasing competence. Production and Operations Management, 10(1): 1-15.

Narasimhan, R., Swink, M. \& Kim, S. W. (2005). An exploratory study of manufacturing practice and performance interrelationships: Implications for capability progression. International Journal of Operations \& Production Management, 25(9/10): 10131033.

Ndubisi, N. O. \& Salleh, A. S. (2006). SMEs in Malaysia: Development Issues. In N. A. Ndubisi and A. S. Salleh, Small and Medium Enterprises (SMEs): Malaysian and Global Perspectives. Selangor, Malaysia Pearson/Prentice Hall. 
NSDC (2010). SME Annual Report 2009/10: Transformation to the New Economic Model. Kuala Lumpur: SME Corporation Malaysia.

O'Dwyer, M., Gilmore, A. \& Carson, D. (2009a). Innovative marketing in SMEs. European Journal of Marketing, 43(1/2): 46-61.

O'Dwyer, M., Gilmore, A. \& Carson, D. (2009b). Innovative marketing in SMEs: An empirical study. Journal of Strategic Marketing, 17(5): 383-396.

O'Regan, N. \& Ghobadian, A. (2004). The importance of capabilities for strategic direction and performance. Management Decision, 42(2): 292-313.

Pearce, J. A. \& Robinson, R. B. (2000). Formulation, Implementation, and Control of Competitive Strategy Boston: Irwin McGraw-Hill.

Porter, M. E. (1980). Competitive Strategy: Techniques for Analyzing Industries and Competitors. New York: The Free Press.

Porter, M. E. (1985). Competitive Advantage: Creating and Sustaining Superior Performance. New York: The Free Press

Prajogo, D. I. (2007). The relationship between competitive strategies and product quality. Industrial Management + Data Systems, 107(1): 69-83.

Rashid, M. Z. A. \& Chacko, G. K. (1999). Strategy selection to enhance exports of the Malaysian electrical and electronic industry. Asia Pacific Journal of Marketing and Logistics, 11(1): 16-27.

Rosenzweig, E. D., Roth, A. V. \& Dean, J. W. (2003). The influence of an integration strategy on competitive capabilities and business performance: An exploratory study of consumer products manufacturers. Journal of Operations Management, 21(4): 437456.

Stalk, G., Evans, P. \& Shulman, L. E. (1992). Competing on capabilities: The new rules of corporate strategy. Harvard Business Review, 70(2): 54-66.

Stevens, G. C. (1989). Integrating the supply chain. International Journal of Physical Distribution \& Logistics Management, 19(8): 3-8.

Swartz, T. A. \& Iacobucci, D. (2000). Handbook of Services Marketing \& Management. Thousand Oaks, CA: Sage.

Swink, M. \& Hegarty, W. H. (1998). Core manufacturing capabilities and their links to product differentiation. International Journal of Operations \& Production Management, 18(4): 374-396.

Tambunan, T. (2007). Entrepreneurship development: SMEs in Indonesia. Journal of Developmental Entrepreneurship, 12(1): 95-118. 
Teece, D. J., Pisano, G. \& Shuen, A. (1997). Dynamic capabilities and strategic management. Strategic Management Journal, 18(7): 509-533.

Thomas, A. S., Litschert, R. J. \& Ramaswamy, K. (1991). The performance impact of strategy-manager coalignment: An empirical examination. Strategic Management Journal, 12(7): 509-522.

Valsamakis, V. P. \& Sprague, L. G. (2001). The role of customer relationships in the growth of small- to medium-sized manufacturers. International Journal of Operations \& Production Management, 21(4): 427-445.

Wafa, S. A., Noordin, R. \& Kim-Man, M. (2005). Strategy and performance of small and medium-size enterprises in Malaysia. The International Conference in Economics and Finance (ICEF). Labuan, Universiti Malaysia Sabah.

Watts, C. A., Kee Young, K. \& Hahn, C. K. (1992). Linking purchasing to corporate competitive strategy. International Journal of Purchasing and Materials Management, 28(4): 2-8. 